\title{
Tumor aggressiveness risk factors in the differentiated thyroid carcinoma
}

\author{
Lukas $\mathrm{J}^{1,2}$, Hitnausova $\mathrm{B}^{3}$, Jiskra $\mathrm{J}^{4}$, Syrucek $\mathrm{M}^{5}$ \\ Department of Otolaryngology - Head and Neck Surgery, Na Homolce Hospital, Prague, Czech Republic. \\ jluk@seznam.cz
}

\section{ABSTRACT}

BACKGROUND: The differentiated thyroid carcinoma (DTC) is the most frequent malignancy in endocrinology (95\%). Our aim was to retrospectively compare risk factors of tumor aggressiveness and history of thyroid disease in patients with conventional DTC and differentiated thyroid microcarcinoma (DTMC).

METHODS: Retrospective analysis of 167 patients after total thyroidectomy with a histologically confirmed DTC, of which 83 patients with conventional DTC $(>1 \mathrm{~cm})$ and 84 with DTMC $(\leq 1 \mathrm{~cm})$. The analyzed factors were tumor size, its aggressiveness (i.e. multifocal or bilateral occurrence, angioinvasion, extracapsular growth, presence of cervical lymph node metastases, distant metastases, and early local relapse) and medical history of thyroid diseases.

RESULTS: In the DTMC group, there were 80/84 (95.2 \%) papillary carcinomas compared with 58/83 (69.9\%) in the conventional DTC group $(p=0.001)$. Patients with DTMC were significantly older than those with conventional DTC $(p=0.006)$. In the conventional DTC group, there was a significantly higher occurrence of angioinvasion and extracapsular growth $(p=0.001)$, cervical lymph node metastases $(p=0.013)$, relapse $(p=0.018)$, and distant metastases $(p=0.007)$, compared with the DTMC group.

CONCLUSION: In patients with DTMC, there was a significantly lower presence of risk factors of tumor aggressiveness, compared with the conventional DTC group (Tab. 2, Ref. 17). Text in PDF www.elis.sk.

KEY WORDS: differentiated thyroid cancer, microcarcinoma, thyroidectomy.

\begin{abstract}
Abbreviations: TSH - thyroid-stimulating hormone, rhTSH - recombinant human thyrotropin, US - ultrasound, CT - computed tomography, PET/CT - positron emission tomography/ computed tomography, Tg - thyroglobulin, MTC- medullary thyroid carcinoma, PTC-papillary thyroid carcinoma, FTC -follicular thyroid carcinoma
\end{abstract}

\section{Introduction}

The differentiated thyroid carcinoma (DTC) constitutes $95 \%$ of all endocrine cancers (1). Although the disease relapse is reported in $15-27 \%$ of cases (2), mortality reaches only $0.5 \%$ (3). Risk factors include previous radiation exposure, long-term increased TSH levels, iodine deficiency, and positive history of the disease

${ }^{1}$ Department of Otolaryngology - Head and Neck Surgery, Na Homolce
Hospital, Prague, Czech Republic, ${ }^{2}$ Department of Otolaryngology, Faculty
of Medicine, Charles University, Pilsen, Czech Republic, ${ }^{3}$ Department of
Endocrinology, Na Homolce Hospital, Prague, Czech Republic, ${ }^{4}$ The 3 rd
Department of Medicine - Department of Endocrinology and Metabolism,
1 st Faculty of Medicine, Charles University in Prague and General Univer-
sity Hospital in Prague, Czech Republic, and ${ }^{5}$ Department of Pathology,
Na Homolce Hospital, Prague, Czech Republic

Address for correspondence: J. Lukas, MD, PhD, Department of Otolaryngology - Head and Neck Surgery, Nemocnice Na Homolce, Roentgenova 2, CZ-150 30 Prague 5, Czech Republic.

Phone: +420.257573075 , Fax: +420.257272850 in the family. Furthermore, certain significance is attributed to the total environmental pollution, so-called endocrine disruptors (4). The differentiated thyroid carcinoma is derived from follicular epithelium and its most common histological form is the papillary carcinoma ( $80 \%$ of cases). In the past 40 years, there has been a general increase in the newly diagnosed differentiated thyroid carcinomas with tumors sized $\leq 1 \mathrm{~cm}$, so-called microcarcinomas (DTMC). Even though these are little advanced cancers with a very good prognosis, there have been reported some cases with aggressive behavior $(5,6)$.

The aim of this retrospective study was to determine the occurrence of DTC and percentage of DTMC in operated patients and analyze the risk factors that can have an impact on aggressive behavior of this cancer, as well as to compare the results in DTMC and conventional DTC.

\section{Material and methods}

We carried out a retrospective analysis of 167 patients with histopathological findings of a differentiated thyroid carcinoma subjected to total thyroidectomy (TTE) performed in the Department of Otolaryngology - Head and Neck Surgery, Na Homolce Hospital in Prague. According to the TNM Classification of Malignant Tumours, 7th Edition, Czech version 2011, patients were divided into two groups: differentiated carcinoma sized $>1 \mathrm{~cm}$ (conventional DTC) and differentiated carcinoma sized $\leq 1 \mathrm{~cm}$ 
Tab. 1. Clinicopathological and demographic data of patients in the study.

\begin{tabular}{|c|c|c|c|c|}
\hline & Total $(n=167)$ & DTC $(n=83)$ & DTMC $(n=84)$ & $\mathrm{p}$ value \\
\hline Age & $49.6 \pm 14.3$ & $46.5 \pm 14.4$ & $52.6 \pm 13.6$ & 0.006 \\
\hline Sex - women - n (\%) & $133(79.6 \%)$ & $63(75.9 \%)$ & $70(83.3 \%)$ & 0.254 \\
\hline Average tumor size (mm) & $14.4 \pm 11.8$ & $23.4 \pm 10.7$ & $5.6 \pm 2.7$ & 0.001 \\
\hline \multicolumn{5}{|l|}{ Histological type - n (\%) } \\
\hline Papillary carcinoma & $138(82.6 \%)$ & $58(69.9 \%)$ & $80(95.2 \%)$ & 0.001 \\
\hline Classic papillary v. & $75(44.9 \%)$ & $31(37.3 \%)$ & $45(53.4 \%)$ & \\
\hline Follicular v. & $55(32.9 \%)$ & $24(28.9 \%)$ & $31(36.9 \%)$ & \\
\hline Oncocytic v. & $2(1.2 \%)$ & $1(1.2 \%)$ & $1(1.2 \%)$ & \\
\hline Papillo-follicular v. & $6(3.6 \%)$ & $2(2.4 \%)$ & $4(4.8 \%)$ & \\
\hline Follicular carcinoma & $26(15.6 \%)$ & $23(27.7 \%)$ & $3(3.6 \%)$ & 0.001 \\
\hline Minimally invasive $\mathrm{v}$. & $20(12.0 \%)$ & $17(20.5 \%)$ & $3(3.6 \%)$ & \\
\hline Highly invasive v. & $1(0.6 \%)$ & $1(1.2 \%)$ & 0 & \\
\hline Oncocytic carcinoma & $5(2.9 \%)$ & $5(6.0 \%)$ & 0 & \\
\hline $\mathrm{PTC}+\mathrm{FTC}$ & $1(0.6 \%)$ & $1(1.2 \%)$ & 0 & \\
\hline $\mathrm{PTC}+\mathrm{MTC}$ & $1(0.6 \%)$ & 0 & $1(1.2 \%)$ & \\
\hline Multifocality - n (\%) & $43(25.7 \%)$ & $25(30.1 \%)$ & $18(21.4 \%)$ & 0.219 \\
\hline Bilaterality & $25(58.1 \%)$ & $16(64 \%)$ & $9(50.0 \%)$ & 0.532 \\
\hline Angioinvasion & $22(13.2 \%)$ & $18(21.7 \%)$ & $4(4.8 \%)$ & 0.001 \\
\hline Cervical lymph node metastases & $18(10.8 \%)$ & $14(16.9 \%)$ & $4(4.8 \%)$ & 0.013 \\
\hline Extracapsular growth & $38(22.7 \%)$ & $32(38.5 \%)$ & $6(7.1 \%)$ & 0.001 \\
\hline Relapse & $9(5.4 \%)$ & $8(9.6 \%)$ & $1(1.2 \%)$ & 0.018 \\
\hline Distant metastases & $7(4.2 \%)$ & $7(8.4 \%)$ & 0 & 0.007 \\
\hline
\end{tabular}

(DTMC - differentiated thyroid microcarcinoma). In addition to tumor size, other risk factors were analyzed, such as tumor aggressiveness [multifocal presence of tumor lesions (unilateral/ bilateral), extracapsular growth, presence of angioinvasion, finding of cervical lymph node and distant metastases and early local relapse] and history of thyroid diseases (chronic lymphocytic thyroiditis, eufunctional nodular goiter, and thyrotoxicosis) at the time of diagnosis. The early local tumor relapse and presence of regional nodular or distant metastases were determined on the basis of positive findings by US, CT and PET/CT imaging methods and positive serum concentration of thyroglobulin $(\mathrm{Tg})>2.0 \mathrm{ng} /$ $\mathrm{ml}$ under postoperative hypothyrodism or after rhTSH stimulation following the total thyroidectomy 6-12 months after the surgery.

\section{Results}

During the monitored period of 2005-2014, the total thyroidectomy (TTE) was carried out in 874 patients. The differentiated thyroid carcinoma was verified in 167 patients $(19.1 \%)$; one-stage or two-stage TTE was carried out in $132(79 \%)$ and 35 cases, respectively. DTMC was verified in 84 operated patients (50.3\%), and conventional DTC in 83 patients $(49.7 \%)$. In DTMC, the papillary type of carcinoma was verified in 80 cases $(95.2 \%)$, compared with 58/83 (69.9\%) in conventional DTC ( $\mathrm{p}=0.001)$. In the DTMC group, there were 62 patients older than $\geq 45$ years (73.8\%), compared with 38 patients in the conventional DTC group $(\mathrm{p}=0.001)$. Out of the total number of 167 DTC patients, there were 133 women $(79.6 \%)$ and the men/women ratio was $4: 1$. Nevertheless, in the sex representation, there was no significant difference between both groups $(\mathrm{p}=0.254)$. The average age of patients with DTMC was 52.6 years (range 17-76 years) as compared with 46.5 years (range $22-76$ years) in conventional DTC $(\mathrm{p}=0.006)$. An average DTC size was $23.4 \pm 10.7 \mathrm{~mm}$ and DTMC size was $5.6 \pm 2.7 \mathrm{~mm}$. In the conventional DTC, there were significantly higher frequencies of angioinvasion and extracapsular growth $(\mathrm{p}=0.001)$, cervical lymph node metastases $(\mathrm{p}=0.013)$, relapse $(\mathrm{p}=0.018)$ and distant metastases $(\mathrm{p}=0.007)$ compared with DTMC (Tab. 1). We did not find significant differences in the presence of multifocality $(\mathrm{p}=0.219)$ or bilaterality $(\mathrm{p}=0.532)$ and history of thyroid diseases in both groups (Tab. 2).

\section{Discussion}

The differentiated thyroid microcarcinoma (DTMC) is almost always of papillary form (7), which was also confirmed by our analysis. In most patients, these are cancers with a very good prognosis, even in the case of cervical lymph node metastases (8). The long-term prognosis for patients with DTMC is so good that it is difficult to achieve further significant prognosis improvement and the occurrence of relapse is low (about $3 \%$ ) (9). One of the explanations of such good outcomes is that the presence of risk factors is undoubtedly connected with the tumor size. Some authors consider DTMC to be of a clinically low significance and suggest

Tab. 2. Preoperative benign thyroid disease and incidence of DTC and DTMC.

\begin{tabular}{lccc}
\hline $\begin{array}{l}\text { Preoperative } \\
\text { thyroid disease }\end{array}$ & DTC & DTMC & p value \\
\hline $\begin{array}{l}\text { Chronic lymphocytic } \\
\text { thyroiditis }\end{array}$ & $29(34.5 \%)$ & $33(39.3 \%)$ & 0.674 \\
\hline $\begin{array}{l}\text { Eufunctional nodular } \\
\text { goiter uni/multi- nodular }\end{array}$ & $53(63.9 \%)$ & $46(54.8 \%)$ & 0.299 \\
$\begin{array}{l}\text { Thyreotoxicosis, } \\
\text { toxic adenoma }\end{array}$ & $1(1.2 \%)$ & $5(5.9 \%)$ & 0.218 \\
\hline
\end{tabular}


renaming it to papillary thyroid microtumor (10). At present, the radioiodine ablation is indicated in the case of presence of unfavorable prognostic factors such as local extrathyroidal invasion, angioinvasion, tumor multifocality and presence of lymph node metastases. We did not find any significant difference between multifocal tumors and bilaterality. However, some authors such as Kuhn et al (11) and others (12) imply that it is the multifocality of the papillary microcarcinoma that poses the increase in the risk of distant metastases. There can be three different forms of the disease relapse, namely lymph node metastases, local spread, and presence of distant metastases (13). The relapse occurs more often in regional lymph nodes, which is usually caused by the indolent behavior of the disease in these regional lymph nodes, while the relapse in them is usually identified in 3-4 years. This is most probably the disease persistence with a possible spread rather than a true relapse (14). Local relapse and metastases in regional lymph nodes represent a different entity, both biologically and in connection with repeated surgery. Compared with a selective neck dissection, a repeated surgery of the local relapse is associated with a higher risk of postoperative complications, especially with an injury of the recurrent laryngeal nerve, parathyroid glands, and trachea. The presence of cervical lymph node metastases, and small-scale surgery rather than complete thyroidectomy have been regarded as significant prognostic factors of relapse and mortality in the papillary thyroid microcarcinoma (15).

\section{Conclusion}

Although the patients with DTMC were more often older than 45 years, they had significantly lower occurrence of angioinvasion, extracapsular growth, cervical lymph node metastases, and early relapse in comparison with those with conventional DTC. We did not find any significant differences in the occurrence of multifocality, bilaterality and preoperative thyroid disease. Our results comply with the recommendations stipulated in the guidelines for the diagnosis and therapy of differentiated carcinoma which allow less radical surgeries than total thyroidectomy, i.e. hemithyroidectomy, in the absence of risk factors for tumor aggressiveness, as well as in case of a solitary and well-differentiated thyroid microcarcinoma $(16,17)$.

\section{References}

1. Sipos JA, Mazzaferri EL. Thyroid cancer epidemiology and prognostic variables. Clin Oncol 2010; 22: 395-404.

2. Ortiz S, Rodriguez JM, Parrilla P, Peréz D, Moreno-Gallego A, Rios A, Soria T. Recurrent papillary thyroid cancer:analysis of prognostic factors including the histological variant. Eur J Surg 2001; 167: 406-412.

3. National Cancer Institute. SEER Stat Fact Sheets: Thyroid Cancer. Available at: 2014 http://seer.cancer.gov/Starfacts/html/thyro.html.

4. Vlček P. Thyroid cancer-an overview of diagnostics and treatment. Postgrad Med 2013; 1: 78-83.

5. Pacini F. Thyroid microcarcinoma. Best Pract Res Clin Endocrinol Metab 2012; 26: 421-429.

6. Roti E, Degli Uberti EC, Bondanelli M, Braverman LE. Thyroid papillary microcarcinoma: a descriptive and meta-analysis study. Eur J Endocrinol 2008; 159: 659-673.

7. Garcia-Mayor RV. Papillary thyroid microcarcinoma: How deal this epidemic? Endocrinol Metab Int J 1(1): 0005. DOI:10.15406/ emij.2015.01.0005.

8. Piana S, Ragazzi M, Tallini G, de Biase D, Ciarrocchi A, Frasoldati A, Rosai J. Papillary thyroid microcarcinoma with fatal outcome: evidence of tumor progression in lymph node metastases: report of 3 cases, with morphological and molecular analysis. Hum Pathol 2013; 44: 556-565.

9. Hay ID, Hutchinson ME, Gonzales T-Losada T, Mclver B, Reinalda ME et al. Papillary thyroid microcarcinoma: A study of 900 cases observed in a 60-year period. Surgery 2008; 144: 980-987.

10. Rosai J, LiVolsi VA, Sobrinho-Simoes M, Williams ED. Renaming papillary microcarcinoma of the thyroid gland: the Porto proposal. Int $\mathrm{J}$ Surg Patho, 2003; 11: 249-251.

11. Kuhn E, Teller L, Pinana S, Rosai J, Merino MJ. Different clonal origin of bilateral papillary thyroid carcinoma, with a review of the literature. Endocrine Pathol 2012; 23: 101-107.

12. Azaitou-Panayoitou K, Capezzone M, Pacini F. Clinical features and therapeutic implications of papillary thyroid microcarcinoma. Thyroid 2007; 17(11): 1085-1092.

13. Grant CS. Recurrence of papillary thyroid cancer after optimized surgery. Gland Surgery 2015; 4 (1): 52-62.

14. Onkendi EO, McKenzie TJ, Richards ML et al. Reoperative experience with papillary thyroid cancer. World J Surg 2014; 38: 645-652.

15. Yu XM, Wan Y, Sippel RS, Chen H. Should all papillary thyroid microcarcinomas be aggressively treated? An analysis of 18.445 cases. Ann Surg 2011; 254 (4): 653-660.

16. Pacini F, Schlumberger M., Dralle $H$ et al. European consensus for the management of patients with differentiated thyroid carcinoma of the follicular epithelium. Eur J Endocrinol 2006; 154 (6):787-803.

17. Hay I D, Grant C S, Bergstralh EJ et al. Unilateral total lobectomy: is it sufficient surgical treatment for patients with AMES low-risk papillary thyroid carcinoma? Surgery 1998; 124 (6): 958-964.

Received May 4, 2015. Accepted August 18, 2015. 